\title{
An assessment of health practises among small-scale farmers in Kwara State, Nigeria
}

\author{
Jones A. Akangbe', Abidemi O. Asiyanbi', Ayanda F. Ibraheem¹', Komolafe E. Sola', \\ Jubril Olayinka Animashaun² \\ ${ }^{1}$ Department of Agricultural Extension and Rural Sociology, University of Ilorin, Nigeria \\ 2 Department of Agricultural Economics and Farm Management, University of Ilorin, Ilorin, Nigeria
}

Akangbe JA, Asiyanbi AO, Ibraheem AF, Sola KE, Animashaun JO. An assessment of health practises among small-scale farmers in Kwara State, Nigeria. Ann Agric Environ Med. 2015; 22(3): 488-490. doi: 10.5604/12321966.1167720

\begin{abstract}
Objective. The study examines the personal health practices of small scale farmers in Kwara State, Nigeria.

Materials and Methods. Primary data were obtained using a well-structured questionnaire which was distributed to 120 small scale farmers. Descriptive statistical techniques such as frequency count, percentages were used, as well as Pearson Product Moment correlation and analysis for empirical analysis.

Results. Results revealed that more than half (55\%) smoke cigarettes, about $48 \%$ drink alcohol to a very great extent, while the majority (64.5\%) indicated they have not been screened to know their HIV status. On a positive note, the results further show that the majority $70 \%, 53.3 \%, 80 \%$ and $73.3 \%$ indicated that they eat a balance diet, engage in physical activity, practice safer sex, and regularly visit a health care centre, respectively. It also revealed that $77 \%$ have not attended any training on healthy living. The results of PPMC showed that the health knowledge of respondents had significant $(p<0.01)$ influence on practices like cigarette smoking, eating a balance diet and regular visits to a health care centre.

Conclusion. It was concluded that health threatening practices such as cigarette smoking and drinking alcohol among the majority of the respondents, coupled with their lack of health knowledge from health professionals, contributes to the poor health status of respondents which eventually negatively influences the labour efficiency of farmers. It is recommended that farmers should endeavour to make use of health literacy programmes introduced to them at local government level, and that the government should provide more of these health literacy programmes.
\end{abstract}

\section{Key words \\ health practices, small scale farmers}

\section{INTRODUCTION}

The health status of small scale farmers is of great concern in Nigeria because of the role they play. There is no doubt that small scale farmers are the major suppliers of food in Nigeria and account for more than $80 \%$ of the total number farmers. Agricultural work involves multiple tasks on a daily and seasonal basis, some of which could expose farmers to frequent injuries, and contact with animals and plants, thus exposing workers to bites, poisoning, infections, parasitic diseases, allergies, exposure to pesticides and other agrochemicals, all of which constitute a major occupational risk which may result in poisoning and death and, in certain cases, workrelated cancer and reproductive impairments. Extreme temperatures due to weather conditions, ergonomic hazards caused by using inadequate equipment and tools, unnatural body position or prolonged static postures, carrying heavy loads, repetitive work, excessively long hours, and other health problems are common among small-scale farmers [1].

Demographic, work related exposures, personal health practices, and occupational health and safety measures have each been identified as independent risk factors for farm injury in the recent past. Individual level risk factors include personal health behaviours and physiological factors such as age and co-morbid conditions. The Second Report of the Public Health Agency of Canadians, modified [2], stated that personal health practices and coping skills refers to

Address for correspondence: Jones A. Akangbe, Department of Agricultural Extension and Rural Sociology, University of Ilorin, Nigeria

E-mail: jonesakangbe@gmail.com, reals4u@yahoo.com

Received: 04 January 2013; accepted: 02 February 2015 those actions by which individuals can prevents disease and promote self-care, cope with challenges and develop self-reliance, solve problems and make choices that enhance health. Among farmers [3], it was noted that some individual health practices contributing to their health status are lifestyle factors, such as high rates of alcohol consumption, daily smoking, overweight-obesity, regular exercise, skin protection and regular assessment of health care services [4]. It was also noted that farmers' determinants of farm injuries and farming related diseases include individual and operational characteristics. They further stated that age, gender and sleep habits have been identified as important risk factors at the individual level, while hours worked per week, economic worry and type of work have been identified as risk factors at the operational level.

There is no doubt that health hazards arising from the individual health practices of small-scale farmers can paralyse their relevance to the economy in terms of food production in Nigeria because sometimes, when farmers are sick and still continue to attend the farm, they are counted being part of the complete farm labour force. However, their contribution to farm productivity may be lower because of reduced effort. This situation occurs often during the incubation stages of illness until it becomes full-blown and patient becomes bedridden. [5]. The significant costs and consequences associated with ill-health status includes poorer physical and mental health, reduced productivity and increased risk of injury.

Relying on the primary data gathered from small-scale farmers in Kwara State, the broad objective of the study, therefore, is to examine personal health practices among small- scale farmers. Specifically, the study describes its 
influences on health status and agricultural production output of small-scale farmers.

\section{MATERIALS AND METHOD}

The study was conducted in Kwara State, created on 27 May 1967, located in the North- Central Geographical Zone of Nigeria $\left(11^{\circ} 2\right.$ and $11^{\circ} 45 \mathrm{E}$ and Longitude $2^{\circ} 45$ and $6^{\circ} 40 \mathrm{~N}$ Latitude) [6], and covers a total land area of about 36,825 square kilometres. The State is comprised of 16 Local Governments Areas (LGAs) which are further grouped by the Kwara State Agricultural Development Project (KWADP) into four zones, in accordance with the ecological characteristics, cultural practices and project administration convenience. The zones are: zone A - Baruteen and Kaima LGAs, zone B - Edu and Patigi LGAs, zone C - Asa, Ilorin East, Ilorin South, Ilorin West and Moro LGAs, and Zone D - Ekiti, Ifelodun, Offa, Oyun, Isin and Oke-Ero LGAs.

A three-stage random sampling technique was used in selecting the sample for this study. The first stage involved the random selection of two zones (zones B and D) from the four KWADPs zones in Kwara State. The second stage involved the random selection of four Local Governments Areas from the 9 LGAs in zones B and D. Zone D consists of seven LGAs and Zone B consists of two LGAs. Three LGAs - Ekiti, Ifelodun and Offa - were randomly selected in Zone D, while Edu LGA was randomly selected in Zone B. The third stage involved the random selection of 20 farmers each from Ekiti, Ifelodun and Offa, while 60 farmers were randomly selected from Edu LGA. A total of 120 farmers were used as the sample size for this study.

The study adopted a survey design to examine the health and coping practices among the small-scale farmers. Information was sought about how the practices affected their health status and agricultural production outputs through an in-depth interview and a closed end questionnaire. The questioners were administered individually to the respondents with options such as: very great extent, some extent, and not at all. Statistical tools used to analyse data were simple percentages, mean and standard deviation. Mean were calculated from a scale of 1- not at all, 2 - to some extent and 3 - a very great extent.

\section{RESULTS AND DISCUSSION}

The health practices data presented in Table 1 show that more than a half $(38.3 \%$ and $16.7 \%)$ of the small-scale farmers

Table 1. Percentage Distribution of Health Practices of Small scale Farmers

\begin{tabular}{lccccc}
\hline Health Practices & $\begin{array}{c}\text { Very great } \\
\text { extent }\end{array}$ & $\begin{array}{c}\text { Some } \\
\text { extent }\end{array}$ & Not at all & Mean & S. D \\
\hline Cigarette smoking & 38.3 & 16.7 & 45 & 1.93 & 0.91 \\
\hline Eating Balance diet & 8.3 & 70 & 21.7 & 1.86 & 0.53 \\
\hline Keeping active physical & 12.5 & 53.3 & 34.2 & 1.78 & 0.65 \\
\hline Manage Stress by relaxing & 26.7 & 53.3 & 20 & 2.07 & 0.68 \\
\hline Alcohol intake & 48 & 11.7 & 40.3 & 2.07 & 0.94 \\
\hline Practicing Safer sex & 20 & 60 & 20 & 2 & 0.63 \\
\hline Screened for HIV/AIDs, & 12.5 & 23.3 & 64.2 & 1.43 & 0.70 \\
\hline Hepatitis etc & 11.7 & 73.3 & 15 & 1.96 & 0.51
\end{tabular}

Note: Mean were calculated from a scale of $1=$ Not at all, $2=$ some extent and $3=$ very great extent smoke at very great extent, and to some extent, respectively (mean $=1.93 ; \mathrm{S} . \mathrm{D}=0.91$ ). There is no doubt that these farmers are prone to the risk of the harm that cigarette smoking could cause and negatively affect their health status. According to a report [7], tobacco smoke contains chemicals that are harmful to both smokers and non-smokers, and breathing even a small amount of tobacco smoke can be harmful. Of the more than 7,000 chemicals in tobacco smoke, at least 250 are known to be harmful, including hydrogen cyanide, carbon monoxide, and ammonia. Based on this report, a poor health status awaits the small-scale farmers, either now or later, which will definitely have a negatively influence on their agricultural productivity.

The results on the consumption of alcohol (mean score $=$ $2.07, \mathrm{s.d}=0.94)$ revealed that a high number $(48 \%)$ drink to a great extent, $11.7 \%$ indicated that they drink only to some extent, and $40.3 \%$ stated that they are non-drinkers of alcohol [8], stating that the effects of alcohol on the liver include inflammation (alcoholic hepatitis) and cirrhosis (progressive liver scarring). They further stated that the risk ofr liver disease is related to how much a person drinks: the risk is low at low levels of alcohol consumption but increases steeply with higher levels of consumption. This suggests that the latter effect of alcohol intake among the majority respondents who drink to great extent will result in a poor health status, and thus reduce agricultural productivity.

Table 1 shows that screening for HIV/AIDs, hepatitis, etc., is not a common health practice among the respondents: $64 \%$ indicated that they have never been screened before. Although the results also indicated that $60 \%$ of the respondents practice safer sex to some extent, this implies that the small-scale farmers in the study area were aware of sexually transmitted diseases and preventive measures, but their ignorance about their HIV status could make them vulnerable and increase the chances of the spread of HIV which, in turn, poses a threat to their relevance to food production in the study area. In an observation by [9], it was found that HIV/AIDS is a major threat to agriculture and food security because it reduces agricultural productivity and diminishes the availability of food through direct loss of family labour, and reduction in time allocated to farming. With specific regard to farming households, [10] also noted two direct impacts:

1) labour quality measured in terms of productivity is reduced when an HIV-infected person is ill, and the supply of such household labour falls when the person dies;

2) the availability of cash to the family is affected as the household financial reserves would have to be used for medical treatment of the sick, and for meeting funeral costs in the case of death.

On a positive note, the results also revealed that the majority $70 \%, 53 \%$ and $53.3 \%$ of the respondents indicated, respectively, that they eat a balance diet, keep physical active, and manage stress by relaxing to some extent [11]. Physical activity is a fundamental way of improving the physical and mental health of individuals. Diet and physical activity influence health, both together and separately, although the effects of diet and physical activity on health often interact, particularly in relation to obesity; this means that small-scale farmers in the study area were physically healthy to some extent.

The majority $(73.3 \%)$ of the respondents indicated that they visit health care centres to some extent, while $11.7 \%$ indicated that they visit health care centres regularly to a 
very great extent. Such visits for regular medical check-ups could help in checking health status in order to prevent or cure any diseases/illness that might have occurred.

\section{RESULTS}

The results presented in Table 2 shows that 77 (64.2\%) respondents had never attended any training on healthy living related to the farming occupation. Therefore, this large percentage of small-scale farmers in the study area have little or no proper knowledge on practices that could enhance their health and farm safety practices. This category of smallscale farmer would benefit from professional advice to ensure general health care practices, as well as farm safety practices, in order to prevent diseases and farm-related diseases, for them to lead healthy lives.

Table 2. Percentage distribution of small scale farmers on health knowledge

\begin{tabular}{lcc}
\hline Attended training on healthy living & Frequency & Percentage \\
\hline Attend & 43 & 35,8 \\
\hline Dose not attend & 77 & 64,2 \\
\hline Total & 120 & 100 \\
\hline
\end{tabular}

Analysis of Table 3 shows that the selected health practices, such cigarette smoking, eating a balance diet and regular visits to a health centre, indicates a significant relationship with health knowledge. This implies that training attended by small-scale farmers, through which they acquired knowledge about health practices, has a positive relationship with their individual health practices. If more farmers were to be trained, it would positively influence their individual health practices. This is contrary to [12] in which it was found that both trained and untrained farmers failed to observe health and safety regulations, and that a large number of respondents reported no protection of their skin from the heat of the sun.

Table 3. Correlation matrix of selected Health Practices and Health knowledge of Respondents

\begin{tabular}{lc}
\hline Selected Health Practices & Health knowledge \\
\hline Cigarette smoking & $0.676^{* *}(0.000)$ \\
\hline Eating balance diet & $0.393^{* *}(0.000)$ \\
\hline Regular visit to health center & $0.314^{* *}(0.000)$ \\
\hline
\end{tabular}

** Correlation is significant at the 0.01 (2-tailed)

\section{CONCLUSIONS}

The majority of small-scale farmers in the Kwara State of Nigeria were found to engage in such practices as cigarette smoking and alcohol consumption, and were unaware of their HIV/Aids status, which could jeopardize their good health status. Some positive health practices noted among them are eating a balance diet, practicing safer sex, managing stress by relaxing, regular physical exercise and regular visits to a health care centre; these, of course, are positive signs of a good health status among them. However, a low percentage of health literacy was observed among respondents, and the correlation matrix showed that health knowledge is significant for selected health practices, such as cigarette smoking, eating a balance diet and regular visits to a health care centre. The low level of health literacy about health practices among the farmers might be responsible for the prevalence of such health threatening practices. The negative health practices noted are still capable of worsening the farmers' health status, thereby reducing the agricultural relevance of small scale farmers in terms of food production in the study area.

Based on the presented findings, it is recommended that farmers should be more involved in health literacy programmes conducted by health professionals and health service providers introduced by the government and NGOs. Their active participation in such programmes will provide opportunities for the farmers to create an environment that empowers and encourages behavioural changes in individuals, families and communities, in order to make positive, lifeenhancing decisions on healthy diets, patterns of physical activity and prevention of non-communicable diseases, and also on the dangers of cigarette smoking, excessive intake of alcohol and the importance of knowing their HIV status. The establishment of free HIV/AIDS screening and counselling services to enable farmers to determine their HIV status, and consequently take the necessary steps to prevent the spread of the disease and also manage those already affected.

Extension agents should also intensify efforts to educate small-scale farmers on health safety practices while working on farms, including the importance of good health status to farmers.

\section{REFERENCES}

1. Cordes DH, Rea DF. Farming: A hazardous occupation. Occup Med. 1991; 6: 327-334.

2. What Determines Health. Public Health Agency of Canada, 2003. http: //www.phac-aspc.gc.ca/ph-sp/phdd/determinants/index.html (access: 2011.04.24).

3. Fragar L, Depczynski J. Farm Health and Safety Toolkit for Rural General Practices. Australian Centre for Agricultural Health and Safety, University of Sydney, 2009.

4. Reed DB, Browning SR, Westneat SC, Kidd PS. Personal protective equipment use and safety behaviors among farm adolescents: Gender differences and predictors of work practices. J Rural Health. 2006; 22: 314-320.

5. Allsop, S. and Pidd, K. The nature of drug related harm in the workplace. In: Allsop S, Phillips M, Calogera C (eds.). Drugs and Work: Responding to alcohol and other drug problems in Australian workplaces. IP Communications, Melbourne, 2001.pp 5-20.

6. Publication of the State Planning Commission. Kwara State Planning Commission, 2004

7. U.S. Department of Health and Human Services. Physical Activity and Health: A Report of the Surgeon General. Atlanta, GA: U.S. Department of Health and Human Services, Centers for Disease Control and Prevention, National Center for Chronic Disease Prevention and Health Promotion, 1996.

8. Edwards G, Anderson P, Babor TF, Casswell S, Ferrence R, Giesbrecht N, Godfrey C, Holder HD, Lemmens P, Makela K, Midanik LT, Norstrom T, Osterberg E, Romelsjo A, Room R, Simpura J, Skog O. Alcohol policy and Public Good. New York, NY: Oxford University Press, 1994.

9. Mutangadura G, Mukurazita D, Jackson H. A review of household and community responses to the HIV/AIDS epidemic in the rural areas of sub-Saharan Africa. UNAIDS report 99.39E, Geneva, 1999.

10. Adeoti AI, Adeoti JO. HIV/AIDS and Farms' Production Efficiency in Benue State, Nigeria. African Journal of Biomedical Research 2008; 11: $145-153$.

11. Global Strategy on Diet and Physical activity and Health. WHO Library Cataloguing-Publication data, World Health Organization, 2004.

12. Writte E. Preventing Tobacco-Related Injuries and Deaths In Rural Populations. International Journal of Health Education, 1993. 